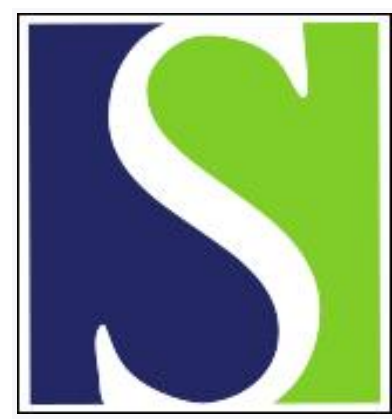

Scand J Work Environ Health 2016;42(1):95-96

https://doi.org/10.5271/sjweh.3536

Published online: 04 Dec 2015, Issue date: 01 Jan 2016

Response by the organizers of the Helsinki criteria updates 2014: Criteria for asbestos-related diseases need periodic updates

by Wolff $\mathrm{H}$, Vehmas T, Oksa P, Tuomi T, Rantanen J, Vainio H

Affiliation: Correspondence to: Dr. Henrik Wolff, Finnish Institute of Occupational Health (FIOH), Topeliuksenkatu 41aA, 00250 Helsinki, Finland. Henrik.Wolff@ttl.fi

Refers to the following texts of the Journal: 1997;23(4):311-316 2015;41(1):5-15 2016;42(1):91-94

This article in PubMed: www.ncbi.nlm.nih.gov/pubmed/26637180 


\section{Response by the organizers of the Helsinki criteria updates 2014: Criteria for asbestos-related diseases need periodic updates}

We want to thank the Collegium Ramazzini for their (unsigned) comments on the 2014 update of the Helsinki criteria (1).

The original Helsinki criteria (criteria) were published in 1997 (2). The Helsinki criteria updates of 2014 consisted of preparatory work in the form of reviews by four work groups on pre-selected topics (subject areas). This was thus not a systematic re-evaluation of the entire criteria and major portions of the 1997 criteria are unaffected by the updates. Based on the reviews, a set of recommendations for each subject area was formulated by the updating group, as a whole, at a meeting in Helsinki. At the beginning of the meeting, declarations of interest information were requested and obtained from all the participants.

Simultaneously with the meeting of the Helsinki criteria updating group, the "International Conference on Asbestos Monitoring and Health Surveillance in Individuals" took place at the same venue. Importantly, all participants in this conference were provided an opportunity to comment on the drafts of the recommendations. The finalized recommendations were then published in this journal as a consensus report (3). The reviews in combination with the recommendations were published separately in a book form. The book is also available on the internet free of cost (4).

Somewhat surprisingly the comments from the Collegium overwhelmingly concern the original 1997 criteria and not the update of 2014. The "pathological diagnosis of the diseases caused by asbestos" referred to in the Collegium's letter concerns mostly methods whereby pathologists can evaluate asbestos exposure by counting asbestos fibers and asbestos bodies in lung tissue. Pathologists are presumed not to be in direct contact with the patients but can only rely on the observations that can be made on the specimens they have received. A major problem with the Collegium's comments is that they seem to want to consider the pathology part of the criteria separately from the rest of the criteria. The criteria do in fact consider work histories as the pre-eminent way of establishing asbestos exposure, as apparently does the Collegium, while "Analysis of lung tissues for asbestos fibres and asbestos bodies can provide data to supplement the occupational histories" (p311, 2).

The Collegium's letter includes a rather cryptic alle- gation of undisclosed financial conflicts of interest. The Collegium does not provide any additional information about this, thus no further comments are possible. In many ways the Collegium's comments appears to be based on a rather large amount of misunderstandings. We list below some short remarks on these comments.

- The one comment that actually concerns the 2014 update has to do with the applicability of the Helsinki criteria to an updated asbestosis classification from 2010 (5). This update of previous guidelines for the histologic diagnosis of asbestosis was organized under auspices of the College of American Pathologists and the Pulmonary Pathology Society and is referred to as CAP-PP by the Collegium.

In the 1997 Helsinki criteria consensus report, the pathological diagnosis of asbestosis required the presence of " 2 or more asbestos bodies in tissue with a section of $1 \mathrm{~cm}^{2}$ or a count of uncoated asbestos fibers that falls into the range recorded for asbestosis in that laboratory". There has not been any change with regards to this requirement in the 2014 update, in contrast to what the Collegium seems to believe.

The 1997 consensus report also noted that, to achieve reasonable comparability between different studies, a standardized system for the histological diagnosis and grading of asbestosis is required and the Roggli-Pratt modification of the CAP-NIOSH system was recommended. Classifications in pathology change with some regularity after new information has become available. After a new version of a classification has been presented, pathologists can be expected to use it. A particular feature of the 2010 version of the asbestosis classification system was that it created a new asbestos-related diagnostic entity "asbestos airways disease", which was for obvious reasons not mentioned in the 1997 consensus report. A similar change concerning the classification of lung cancers was also dealt with in the 2014 updates.

- The consensus report of 1997 does not make recommendations about methods for asbestos fiber analysis.

- The consensus report of 1997 does not advocate obtaining lung tissue solely for the purpose of evaluating asbestos fibers or asbestos bodies.

- The consensus report of 1997 does in fact provide 
threshold values for fibers shorter than $5 \mu \mathrm{m}$ but longer than $1 \mu \mathrm{m}$.

- The 1997 consensus report or rather the reviews associated with it do not mention studies where chrysotile had been detected in mesothelioma tissue, as noted by the Collegium. In the 1997 consensus report chrysotile is however considered to be able to cause mesotheliomas.

- The 1997 consensus report does not include a (biological) threshold of asbestos exposure for the development of asbestos-related lung cancer. What the Collegium seems to refer to is a common civil standard of legal proof: "more likely than not". The 1997 consensus report provides estimates of asbestos exposure needed to reach this legal threshold, equivalent to a relative risk (RR) of 2 . This is discussed in more detail in the "new asbestos-related diseases" section of the 2014 consensus report where it is, among other things, noted that this RR threshold "should not be higher than 2 and can be set at lower levels" (p10,3). The query about the range of risk estimates seems odd. The Collegium would seem to want to somehow involve the lower range, which would lead to a doubling of the cancer risk after an exposure of 200 fiber years instead of 25 fiber years.

Finally it is worth remembering that the Helsinki Criteria are in essence a clinical guideline, not a legal text. During the years it has, however, been found to be useful in legal contexts including law-making. In the Helsinki criteria process, as in other similar consensus processes, many experts with different backgrounds, reached an agreement on what can be considered to be a reasonable synthesis of available data. The usefulness of the criteria comes from this consensus process, which also involved several members of the Collegium. If a number of experts can agree on a specific recommendation, it gives a good indication that there is some firm ground.

With additional research information and new circumstances of exposure, the necessity of future updates is becoming more imminent. In a way, the Collegium's comments can be seen as a call to update the criteria in view of the shift of asbestos usage and exposure to chrysotile that has taken place after 1997.

\section{References}

1. Collegium Ramazzini. Collegium Ramazzini response to 'Asbestos, asbestosis, and cancer, the Helsinki criteria for diagnosis and attribution 2014: recommendations'. Scand J Work Environ Health. 2016;42(1):91-94. http://dx. doi. org/10.5271/sjweh.3535

2. Asbestos, asbestosis, and cancer: the Helsinki criteria for diagnosis and attribution. Scand J Work Environ Health. Tossavainen A (reporter) 1997;23(4):311-6. http://dx.doi. org/10.5271/sjweh.226

3. Asbestos, asbestosis, and cancer, the Helsinki criteria for diagnosis and attribution 2014: recommendations. Wolff H, Vehmas T, Oksa P, Rantanen J, Vainio H. (reporters). Scand J Work Environ Health. 2015 Jan 1;41(1):5-15. http://dx.doi. org/10.5271/sjweh.3462

4. Asbestos, Asbestosis, and Cancer: Helsinki Criteria for Diagnosis and Attribution 2014. Editors: Panu Oksa, Henrik Wolff, Tapio Vehmas, Paula Pallasaho and Heikki Frilander. Finnish Institute of Occupational Health 2014, ISBN 978952-261-459-9. http://www.ttl.fi/en/publications/ Electronic_publications/Documents/Asbestos_web. pdf

5. Roggli VL, Gibbs AR, Attanoos R, Churg A, Popper H, Cagle P, et al. Pathology of asbestosis- An update of the diagnostic criteria: Report of the asbestosis committee of the college of american pathologists and pulmonary pathology society. Arch Pathol Lab Med. 2010;134(3):462-80.

Henrik Wolff, MD, PhD, ${ }^{1 *}$ Tapio Vehmas, MD, PhD, ${ }^{1,2 *}$ Panu Oksa, MD, PhD, ${ }^{* *}$ Timo Tuomi, PhD, ${ }^{1}$ Jorma Rantanen, MD, $\mathrm{PhD},{ }^{2,3^{*}}$ Harri Vainio, MD, PhD ${ }^{1,4 *}$

${ }^{1}$ Finnish Institute of Occupational Health (FIOH), Helsinki, Finland.

2 Helsinki University, Helsinki, Finland.

3 International Commission on Occupational Health (ICOH), Helsinki, Finland.

4 Faculty of Public Health, Kuwait University, Kuwait.

* Reporter of the Helsinki criteria updates of 2014.

Correspondence to: Dr. Henrik Wolff, Finnish Institute of Occupational Health (FIOH), Topeliuksenkatu 41aA, 00250 Helsinki, Finland. [E-mail Henrik.Wolff@ttl.fi] 